\title{
Morphology, sexual dimorphism and size at maturation in topmouth gudgeon (Pseudorasbora parva) from the heated Lake Licheńskie (Poland)
}

\author{
E. Záhorská(1),^, M. Balážová(2), M. Šúrová(1) \\ Received April 8, 2013 \\ Revised July 11, 2013
}

Accepted July 15, 2013

\section{ABSTRACT}

Key-words: interpopulation variability, extreme habitat, invasive species, climate change
To assess the spatial variability in external morphology as well as sexual dimorphism of a non-native population of topmouth gudgeon Pseudorasbora parva within an ontogenetic context, triple regression analysis (distance-based measurements) and statistical tests were applied to data from a heated lake in Poland. Moreover, this population just invaded this extreme and thus special habitat in 2003 , and therefore it represents a novel environment and its first stages of establishment. It has often been reported that topmouth gudgeon is very flexible when reaching new environments and this also shows in forming different phenotypes. We found that mature males and females have not only a different morphology, but also the development of the traits is different. These findings correspond with the specifics of this particular type of habitat.

RÉSUMÉ

Morphologie, dimorphisme sexuel et taille à maturité du Pseudorasbora (Pseudorasbora parva) d'un lac réchauffé, Licheńskie (Pologne)

Mots-clés : variabilité entre populations, habitat extrême, espèces envahissantes, changement climatique
Pour évaluer la variabilité spatiale de la morphologie externe ainsi que le dimorphisme sexuel de la population non autochtone de Pseudorasbora Pseudorasbora parva dans un contexte ontogénétique, l'analyse de régression triple (mesures fondées sur la distance) et les tests statistiques ont été appliqués aux données d'un lac réchauffé en Pologne. Cette population a envahi en 2003 cet extrême et donc spécial habitat qui représente un nouvel environnement aux premiers stades de l'établissement de la population. II est souvent signalé, que Pseudorasbora est très flexible en colonisant de nouveaux environnements et cela se traduit par la formation de phénotypes différents. Nous avons constaté que les mâles adultes et les femelles ont non seulement une morphologie différente, mais aussi un développement des traits différent. Ces résultats correspondent aux spécificités de ce type particulier d'habitat.

\section{INTRODUCTION}

Fish morphology refers to the variety of anatomical design among fish species. Body architecture can be discussed in terms of the characteristic depth, predation style and other swimming specialisations required for the survival success of a given species. For example, the type, size and arrangement of a fish's fins are inextricably related to its ecological niche

(1) Comenius University, Faculty of Natural Sciences, Department of Ecology, Bratislava, Slovakia

(2) Catholic University, Pedagogical Faculty, Department of Biology and Ecology, Ružomberok, Slovakia

* Corresponding author: zahorskae@gmail.com 
(Hogan, 2007). Many authors suggest that morphological differences between populations and/or within populations can be the result of evolution, phenotypic plasticity or both (Kováč et al., 1999; Robinson and Wilson, 1996; Záhorská et al., 2009). Phenotypic plasticity can be defined as 'the ability of individual genotypes to produce different phenotypes when exposed to different environmental conditions' (Pigliucci et al., 2006). This includes the possibility of modifying developmental trajectories in response to specific environmental cues, and also the ability of an individual organism to change its phenotypic state or activity (e.g. its metabolism) in response to variations in environmental conditions (Garland and Kelly, 2006; Fusco and Minelli, 2010). If environments were unchanging, then fixed phenotypes would be favoured. But, because environments are constantly changing, plasticity is often favoured. Indeed, the only way for an individual to adapt to a changing environment is by changing its phenotype. A plastic individual can achieve high fitness in two or more environments, whereas a fixedphenotype specialist that is highly adapted to only one environment would be less fit in a different environment. Likewise, a fixed-phenotype generalist would presumably have only moderate fitness in all environments. In general, phenotypic plasticity should be favoured when it produces higher fitness than a fixed strategy across all environments (Berrigan and Scheiner, 2004).

On the other hand, the variability within the population can also be caused by sexual dimorphism, which is widespread across the animal kingdom. The difference between males and females is not only in reproductive organs, but also in external structures that are not directly related to reproduction (Kitano et al., 2007). Sexual dimorphism can result from a variety of factors, including both sexual and natural selection. Different reproductive roles and intrasexual competition can drive sexual differences in external structures (Andersson, 1994).

Topmouth gudgeon (Pseudorasbora parva) is widespread in nearly all parts of Europe, and since it is one of the most invasive species in recent times its ecology is well known (Gozlan et al., 2010). Topmouth gudgeon populations inhabit variable habitats and display extensive phenotypic divergence in morphological and reproductive traits (Britton et al., 2008; Záhorská et al., 2009; Záhorská and Kováč, 2013). Its males and females have different reproductive roles (Bănărescu, 1999). Females select a clear area and breeding males try to clear the surface of the stones and the surrounding sediment. Each male tries to attract several females, which lay eggs on the stones. After fertilising them, the male actively guards the primitive nests with eggs, by means of tubercules around their mouth (Bănărescu, 1999). In addition to the divergent reproductive roles of the sexes, several morphological structures, such as body size, are important for male and female mate choice in topmouth gudgeon, suggesting that sexual selection may contribute to the evolution of sexual dimorphism in these morphological cues (Wootton, 1984; Schluter, 2001).

Several studies deal with the morphology of topmouth gudgeon (Baruš et al., 1984; Kotusz and Witkowski, 1998; Záhorská et al., 2009), as well as sexual dimorphism, but there is no knowledge about the morphology and sexual dimorphism of topmouth gudgeon from an extreme and thus special habitat with permanently heated water. Besides that the population just invaded this habitat in 2003 . The lake thus represents a novel environment and the topmouth gudgeon population is in its first stages of establishment there. Because of this, the main aims of this study are: 1) to compare if there is any difference in morphology of topmouth gudgeon from a heated lake compared with the knowledge about its morphology in a habitat with a normal temperature regime; 2 ) to test if there is any difference in morphological characters between the males and females; 3 ) to determine the mean size at maturity and to compare if there is differentiation of this parameter between a permanently heated habitat and a habitat with a normal temperature regime; and 4) to try to evaluate the effect of elevated water temperature on an ecosystem after invasion by topmouth gudgeon, and create a possible scenario of climate change and the invasion of topmouth gudgeon.

\section{MATERIALS AND METHODS}

A sample of topmouth gudgeon ( $n=1411$; males $n=426$ and females $n=466$ ) was collected in the litoral zone of Lake Licheńskie which is located in central Poland near Konin in 


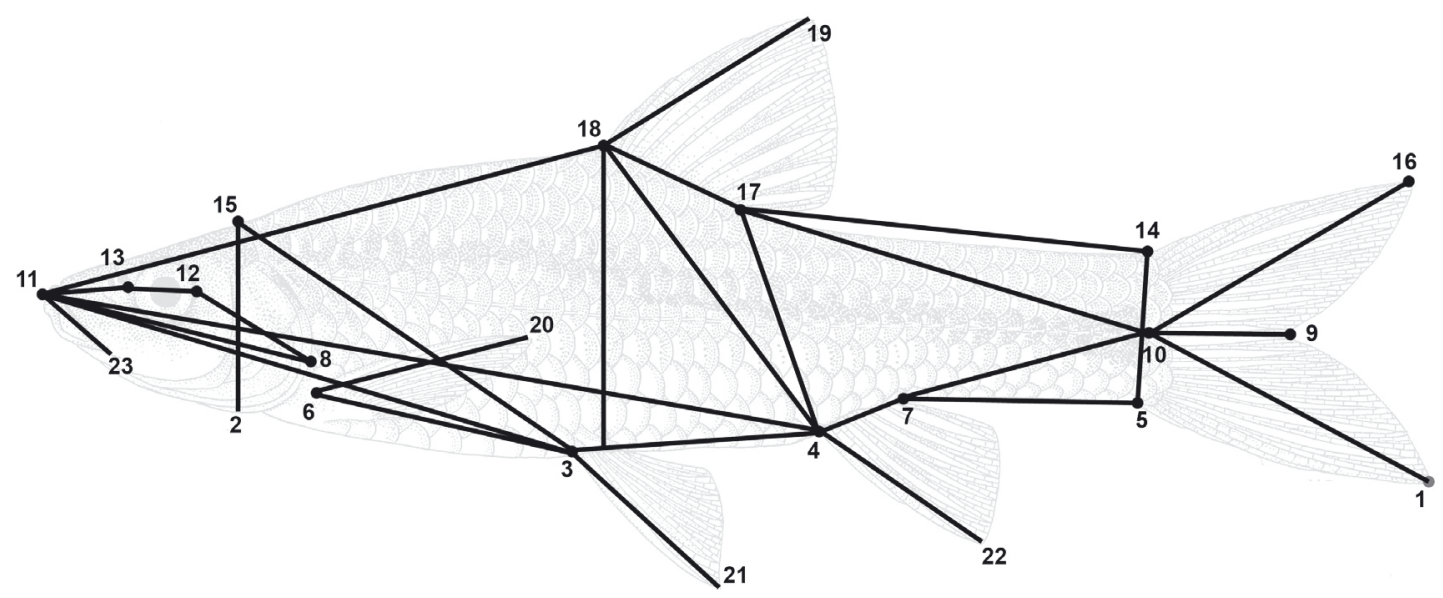

\section{Figure 1}

Scheme of morphometric characters for distance-based measurements taken from Pseudorasbora parva population from heated lake Licheńskie (Poland): head length (11-8); preorbital distance (1113); eye diameter (13-12); postorbital distance (12-8); head depth (15-2); predorsal distance (11-18); prepelvic distance (11-3); preanal distance (11-4); pectoral fin-pelvic fin (P-V) distance (6-3); pelvic finanal fin $(V-A)$ distance (3-4); body depth (18 perpendicular); dorsal fin (anterior end)-anal fin distance (Da-A) (18-4); dorsal fin (posterior end)-anal fin distance (Dp-A) (17-4); postdorsal distance (17-10); postanal distance (7-10); caudal (C) peduncle length (dorsal) (17-14); caudal peduncle length (ventral) (7-5); caudal peduncle depth (14-5); dorsal fin (D) base length (18-17); anal fin (A) base fin length (4-7); pectoral fin $(P)$ length (6-20); pelvic $(V)$ fin length (3-21); caudal upper lobe length (10-16); caudal fork length (10-9); caudal lower lobe length (10-1); dorsal fin length (18-19); anal fin length (4-22); gape (11-23).

the Wielkopolsko-Kujawskie Lakeland $\left(52^{\circ} 16^{\prime} \mathrm{N}, 18^{\circ} 21^{\prime} \mathrm{E}\right)$. Along with four neighbouring lakes, Lake Licheńskie is part of a complex connected by a canal network that serves as the cooling system for the Konin and Pątnów power plants. The high water temperature (the average water temperature increased by $6^{\circ} \mathrm{C}$ ) and its continual exchange throughout the year, substantial industrial and communal pollution, and the stocking of the lakes with herbivorous fish species alien to the endemic ichthyofauna have caused a range of disadvantageous changes in Lake Licheńskie (Kapusta et al., 2008).

Topmouth gudgeon was collected over 7 years (2004-2011) during all seasons (pre-spawning, spawning and post-spawning) with experimental nets (length $5 \mathrm{~m}$, depth $0.8 \mathrm{~m}$ and mesh size $1.0 \mathrm{~mm}$ ). Samples from all sampling dates were united together for the triple regression analysis (TRA) requirements. Captured fish were immediately killed by an overdose of anaesthetic and placed in $4 \%$ formaldehyde solution.

Subsequently, 30 mensural characters including standard length (SL), fork length (FL) and total length (TL; Figure 1, Table I) were measured from digital photographs taken with a Nikon D200 camera using the IMPOR 2.31E software. To examine patterns of relative growth, raw data from 27 morphometric characters were plotted against SL as described by Kováč et al. (1999). TRA was used to test whether body proportions change abruptly rather than gradually (Kováč et al., 1999). This analysis identifies three possible patterns of growth: isometric, allometric and isometric with abrupt change. The F-test (Sokal and Rohlf, 1981) was used to test which model provides the best fit (Kováč et al., 1999).

One-factorial ANOVA was used to test for differences between males and females of topmouth gudgeon for each of the 30 mensural characters.

Discriminant analysis (DCA) was performed on the same variable set. Differentiation of specimens with regard to sex in multidimensional space was determined with Wilk's $\lambda, F$ and $p$ statistics. 
Table I

Mean values, standard deviations (SD), minimum (Min) and maximum (Max) of particular characters (see Figure 1) of topmouth gudgeon (Pseudorasbora parva) from Lake Licheńskie.

\begin{tabular}{|c|c|c|c|c|c|c|c|c|c|c|c|c|}
\hline & \multicolumn{4}{|c|}{ Population } & \multicolumn{4}{|c|}{ Males } & \multicolumn{4}{|c|}{ Females } \\
\hline & \begin{tabular}{|l|} 
Mean \\
\end{tabular} & SD & Min & Max & Mean & SD & Min & Max & Mean & SD & Min & Max \\
\hline SL & 32.77 & 15.27 & 9.26 & 81.89 & 40.84 & 14.89 & 19.21 & 81.89 & 40.43 & 12.85 & 22.96 & 80.35 \\
\hline FL & .38 & 16.82 & 10.35 & 86.46 & 45.20 & 16.19 & 21.18 & 86.25 & 44.92 & 14.11 & 23.95 & 86.46 \\
\hline TL & 39.41 & 17.63 & 14.06 & 89.93 & 48.71 & 16.73 & 23.06 & 89.93 & 48.42 & 14.58 & 26.15 & 89.91 \\
\hline & & & & & & & & & & & & \\
\hline & 26.49 & 2.12 & 19.63 & 35.13 & 25.57 & 1.83 & 19.98 & 32.66 & 25.48 & 1.67 & 20.61 & 30.35 \\
\hline dist & 7.59 & 0.90 & 4.78 & 11.16 & 7.45 & 0.87 & 5.24 & 9.57 & 7.32 & 0.84 & 5.22 & 9.40 \\
\hline eye die & 7.15 & 1.01 & 4.18 & 10.86 & 6.58 & 0.80 & 4.59 & 8.70 & 6.75 & 0.74 & 4.85 & 8.81 \\
\hline pos & 11.96 & 1.08 & 8.93 & 18.13 & 11.75 & 0.89 & 8.97 & 15.24 & 11.57 & 0.85 & 8.93 & 15.04 \\
\hline & 20.11 & 1.16 & 15.81 & 24.69 & 19.95 & 1.02 & 16.81 & 23.50 & 19.69 & 0.96 & 16.67 & 23.48 \\
\hline pre & 53.20 & 2.27 & 45.11 & 68.82 & 52.76 & 1.48 & 48.30 & 57.82 & 52.81 & 1.52 & 47.68 & 59.05 \\
\hline prev & 51.53 & 2.28 & 27.65 & 68.54 & 50.82 & 1.74 & 46.16 & 58.90 & 51.23 & 1.59 & 45.57 & 58.48 \\
\hline prea & 70.63 & 2.90 & 26.92 & 85.94 & 70.77 & 1.66 & 63.33 & 75.97 & 71.03 & 1.76 & 65.04 & 77.45 \\
\hline P-V & 25.04 & 2.55 & 10.57 & 32.87 & 25.10 & 2.03 & 16.06 & 31.21 & 25.92 & 2.29 & 12.70 & 32.87 \\
\hline V-A & 21.48 & 2.08 & 13.89 & 0 & 99 & 1.64 & 14.51 & 27.22 & 21.83 & 1.44 & 16.81 & 26.44 \\
\hline bod & 24.86 & 1.82 & 16.50 & 31.42 & 25.45 & 1.55 & 21.43 & 31.42 & 25.37 & 1.69 & 21.95 & 31.14 \\
\hline Da-A & 29.98 & 2.11 & 19.47 & 40.37 & 30.83 & 1.65 & 26.54 & 37.35 & 30.68 & 1.73 & 19.22 & 37.55 \\
\hline Dp & 20.54 & 1.75 & 13.48 & 28.30 & 21.17 & 1.38 & 17.22 & 26.20 & 21.18 & 1.33 & 17.81 & 25.87 \\
\hline & 37.78 & 1.94 & 27.52 & 45.66 & 37.65 & 1.81 & 31.07 & 43.45 & 38.13 & 1.78 & 29.96 & 43.39 \\
\hline C p & 42.87 & 2.87 & 24.26 & 53.50 & 43.82 & 2.65 & 25.30 & 52.34 & 43.72 & 2.39 & 37.54 & 50.46 \\
\hline pos & 39.27 & 2.01 & 26.65 & 46.14 & 39.60 & 1.73 & 26.65 & 45.08 & 39.84 & 1.63 & 34.63 & 45.04 \\
\hline & 23.73 & 1.92 & 10.07 & 41.42 & 23.74 & 1.62 & 14.31 & 28.22 & 23.67 & 1.44 & 19.14 & 31.68 \\
\hline & 13.05 & 1.28 & 7.51 & 19.94 & 13.27 & 1.19 & 7.51 & 17.26 & 12.91 & 1.07 & 9.60 & 17.64 \\
\hline$A \mathrm{fi}$ & 9.50 & 1.21 & 3.89 & 16.11 & 9.51 & 1.09 & 6.22 & 13.05 & 9.40 & 1.04 & 6.53 & 13.32 \\
\hline & 14.73 & 2.12 & 5.42 & 23.13 & 15.39 & 1.79 & 9.77 & 20.71 & 15.44 & 1.54 & 8.91 & 19.63 \\
\hline & 14.88 & 1.88 & 4.06 & 25.63 & 15.44 & 1.64 & 9.28 & 19.70 & 15.39 & 1.29 & 9.50 & 18.65 \\
\hline C up & 23.91 & 2.61 & 10.63 & 32.15 & 23.67 & 2.39 & 15.69 & 29.32 & 23.95 & 2.07 & 17.57 & 29.24 \\
\hline length & 23.98 & 2.80 & 7.15 & 32.51 & 23.67 & 2.45 & 15.69 & 30.09 & 23.99 & 2.24 & 17.43 & 30.79 \\
\hline D fir & 21.94 & 1.90 & 12.15 & 27.53 & 22.22 & 1.58 & 14.24 & 26.05 & 22.03 & 1.52 & 17.60 & 26.42 \\
\hline Afi & 13.28 & 1.59 & 8.35 & 20.12 & 13.41 & 1.51 & 8.35 & 17.67 & 13.24 & 1.31 & 9.31 & 18.44 \\
\hline$C p$ & 13.16 & 1.02 & 8.03 & 17.02 & 13.44 & 0.84 & 11.35 & 17.02 & 13.14 & 0.85 & 11.07 & 16.28 \\
\hline Gape & 8.87 & 1.74 & 2.30 & 14.49 & 8.68 & 1.48 & 4.63 & 12.60 & 8.71 & 1.28 & 4.83 & 12.55 \\
\hline
\end{tabular}

Mean size at maturity was calculated from the percentage of mature individuals in each size class (at 3-mm SL intervals; Trippel and Harvey, 1987) using the formula of DeMaster (1978), as adapted by Fox (1994):

$$
\alpha=\sum_{x=0}^{w}(x)[f(x)-f(x-1)]
$$

where $\alpha$ is the mean size at maturity (SL), $x$ is the SL in $\mathrm{mm}, f(x)$ is the proportion of fish mature at size $x$, and $w$ is the maximum size in the sample.

\section{RESULTS}

The SL of the whole topmouth gudgeon population $(n=1411)$ ranged from 9.26 to $81.89 \mathrm{~mm}$ (for more details see Table I). Twenty characters were best described by quadratic regression, which represents allometric growth. In fact, 11 measured characters (for more details see Table II) were characterised by negative allometry, which means slower growth of these characteristics compared with growth of SL, and 9 were characterised by positive allometry (faster growth). Six characters were best described by linear regression with isometric growth, and 
just one character was best described by split linear regression with two intervals of isometric growth interrupted with a short interval of allometric growth (Table II).

$\mathrm{SL}$ in mature females $(n=466)$ ranged from $22.96-80.35 \mathrm{~mm}$ (for more details see Table I). As well as in the whole population, quadratic regression with allometric growth predominated (13 characters), where 11 measured characters (for more details see Table II) were characterised by negative allometry and 2 were characterised by positive allometry. Eleven characters were described by linear regression and just three characters with split linear regression (Table II).

SL in mature males $(n=426)$ ranged from 19.21-81.89 (for more details see Table I). Eight characters increased isometrically, and fourteen characters increased allometrically, where 7 measured characters (for more details see Table II) were characterised by negative allometry and 7 were characterised by positive allometry. Five features increased isometrically with an abrupt change (Table II). These characters can be divided into two groups, based on intervals of non-overlap of the standard error: group 1, three characters (body depth, postdorsal distance and caudal upper lobe length) and group 2, two characters (postanal distance and gape). In group 1, all break points fell within the range between 22.33 and $33.50 \mathrm{~mm}$ of SL, while the break points in group 2 fell in the range from 73.47 to $77.86 \mathrm{~mm}$ SL (Table II).

There were significant differences between males and females in 12 mensural characters preorbital distance $(F=5.2462 ; p<0.05)$, eye diameter $(F=10.593 ; p<0.01)$, postorbital distance $(F=9.674 ; p<0.01)$, head depth $(F=15.023 ; p<0.01)$, preventral distance $(F=13.255 ; p<0.001)$, preanal distance $(F=5.1385 ; p<0.05)$, pectoral fin - ventral fin distance $(F=32.107 ; p<0.001)$, dorsal caudal peduncle length $(F=15.178 ; p<0.001)$, postdorsal distance $(F=4.4401 ; p<0.05)$, dorsal fin base length $(F=21.638 ; p<0.001)$, caudal lower lobe length $(F=4.1158 ; p<0.05)$ and caudal peduncle depth $(F=27.913$; $p<0.001$ ).

DCA showed significant differentiation of males and females based on the measured characters $(F=5.9147 ; p<0.0001)$, with $68 \%$ of specimens rightly categorised as the proper sex (65\% in males and $72 \%$ in females). According to Wilk's $\lambda, F$ and $p$ values, there were only eight mensural characters with a significant cumulative effect on the differentiation of males and females. In seven of them there was also a significant difference (eye diameter, head depth, pectoral fin - ventral fin distance, dorsal caudal peduncle length, postdorsal distance, dorsal fin base length and caudal peduncle depth) between males and females. A significant difference between males and females was not found in the eighth character (body depth; based on ANOVA).

Results from DeMaster showed that $100 \%$ of individuals were mature in the size group $33.01-36.00 \mathrm{~mm}$, while the mean size at maturity in females is $31.07 \mathrm{~mm}$ and in males $31.11 \mathrm{~mm}$.

\section{DISCUSSION}

In general, topmouth gudgeon populations show considerable variation in external morphology, which is not only evident in European populations but also in its native range (Gozlan et al., 2010). It would be expected that populations from different latitudes and/or habitats show significant morphological variability, but differences were also found between populations from the same region (Záhorská et al., 2009). This variability can be expressed not only in the formation of different adult phenotypes but also in the manner with which the phenotypes are achieved. Thus, it appears that both the adult phenotype and the patterns of development in introduced topmouth gudgeon can be, in general, highly influenced by local conditions (Záhorská et al., 2009). Although the flexibility of this species in normal thermal regimes has been well described, there has been no information published about how it would cope with extreme conditions, e.g. permanently heated water. In general, the temperature regime has a considerable influence on life histories and extreme temperatures are known to affect various traits, from reproductive parameters (e.g. Dhillon and Fox, 2004) to morphology (e.g. Šumer et al., 2005). 


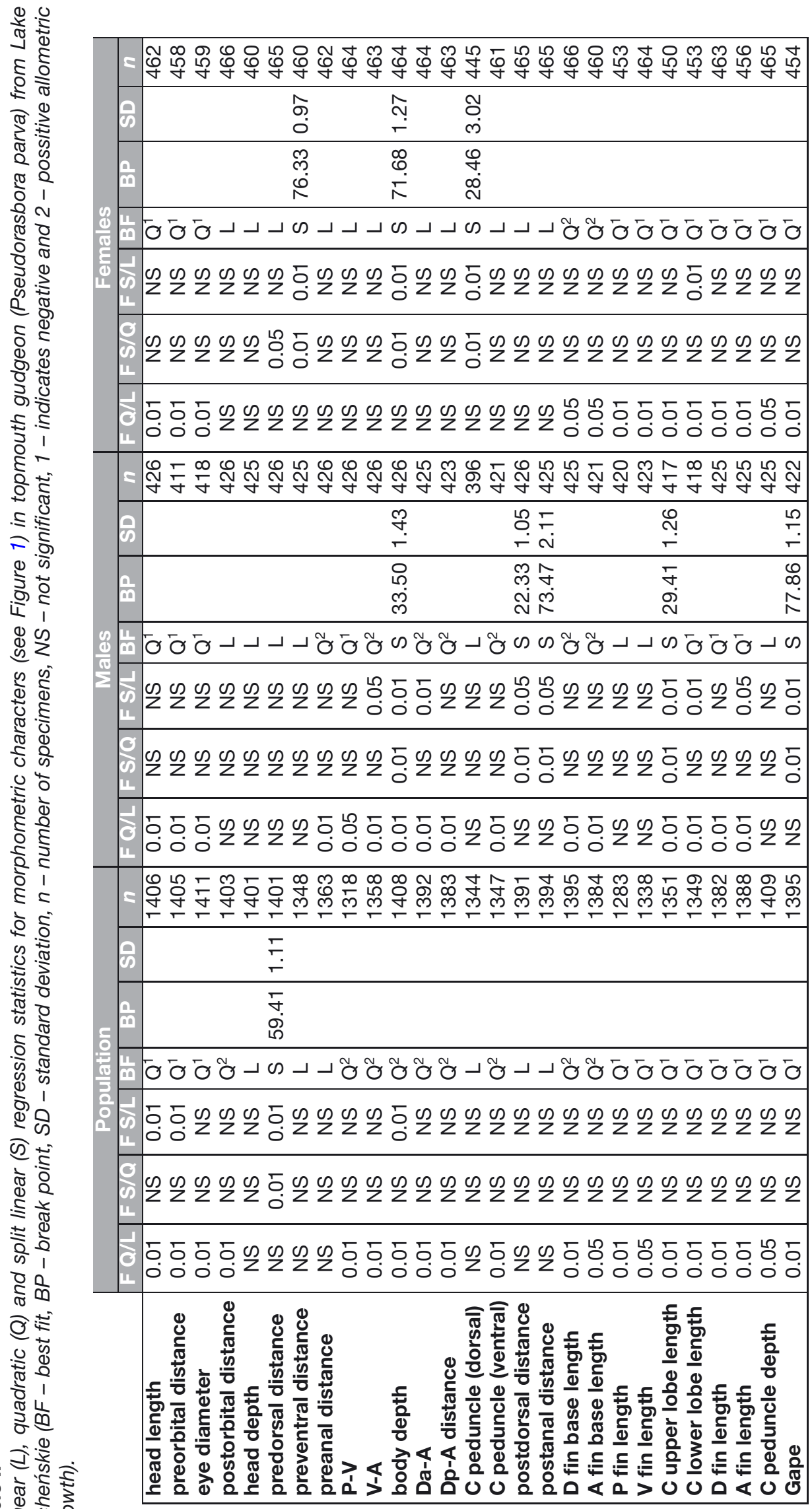


In the majority of topmouth gudgeon populations from Europe (England, France, Slovakia-Draždiak gravel pit, as well as in three populations from Romania; Záhorská et al., 2009), isometric growth predominated over non-isometric. The same phenomenon was also discovered in an invasive population in Poland in a lake with a normal temperature regime (Kotusz and Witkowski, 1998). Allometric growth was more common in just two cases (Šúr pond in Slovakia and Straulesti Lake in Romania; Záhorská et al., 2009). In this regard, it is evident that in the majority of populations isometric growth characterised by early development of external shape (when they were of small size) in individuals is more usual. This leads to a question about the prevalence of allometric growth in the population in Lake Licheńskie (from a habitat with elevated water temperature). Development was characterised by negative allometry in most characters (Table II), which would indicate considerably bigger relative sizes in juveniles compared with adults in characters connected with fin length and with the head (Table II). Strong juvenile growth appears to be an adaptive response to elevated water temperature, as is predicted for most ectotherms (Atkinson, 1994). Also, it would be expected that if the habitat has a stable permanent water temperature (even if it is higher than normal water temperature) the isometric growth would predominate, but it obviously did not. This can possibly be explained by the high reproductive effort of this species, when the young individuals allocate more sources into reproduction and not into somatic growth, and in this way are able to create a higher number of offspring. Indeed, the population changed the reproductive strategy within 8 years of existence in this habitat. It started to produce much more oocytes (mean 5391 oocytes within six spawning periods in 2006-2011) than a population in a stable habitat, e.g. in Slovakia (mean 3000 oocytes; Záhorská et al., 2013a). This led to an increase in the frequency of topmouth gudgeon's occurrence (60\%; Kapusta et al., 2008) and thus it became a dominant fish species in a very short time. Certainly, the complex change in traits such as morphology and reproductive strategy makes this fish such a successful invasive species.

Another important parameter is the size at maturation, because if a population is able to create a large percentage of occurrence in a short time, its chance of successful invasion is even higher. Topmouth gudgeon is a small fish species, reaching maximum lengths of between 60 and $120 \mathrm{~mm}$ TL, maturing usually in the first year of life (Gozlan et al., 2010). Because of this, it is difficult to find statistically significant differences in the age of maturation, though the length at maturation can differ between various populations. The smallest mature female from Lake Licheńskie had just $18.9 \mathrm{~mm} \mathrm{SL}$, though the mean size at maturity within the population was $33.93 \mathrm{~mm} \mathrm{SL}$. In contrast, in populations from Slovakia the mean size at maturity was slightly higher in a disturbed habitat $(34.1 \mathrm{~mm} \mathrm{SL})$, as well as in a stable habitat $(34.9 \mathrm{~mm} \mathrm{SL}$; Záhorská et al., 2013b).

Several authors have attempted to describe sexual dimorphism in P. parva. Males from the River Amur differ from females by their larger size, longer fins (both paired and unpaired) and slightly reduced body depth (Nikolskij, 1956). In contrast, males from a fish farm in Nucet (Romania) had much deeper bodies than females (Bănărescu, 1999). Within the populations from Nichigetsutan (Taiwan) and Kinohama (Japan), mature males are generally larger than females (Okada, 1961). In an invasive population in Poland males differ with larger body size, as well as higher values of minimal body depth, depth of dorsal and anal fins, and length of pectoral fins (Kotusz and Witkowski, 1998).

In our study, we had a comparable sample size of mature males and females, without significant differentiation of SL. Therefore, the investigation of the differences within the characters without the reasonable effect of SL was possible. We found a difference in the body shape of mature males and females (DCA results) which was also followed with different developmental patterns (results from TRA, Table II). In females, the majority of characters were best characterised by negative allometry (the same characters as the characters for the whole population, Table II) which means faster growth of traits in juveniles than in adult females. As in the whole population, these traits were connected with length of fins and size of the head. Just three characters connected with body length and depth developed with split linear regression, which would represent the life-history interval during which some remodelling of the 
external body shape occurs. Two of these characters were in the same interval, but it was at a big size (71-76 $\mathrm{mm}$ of SL), meaning a change while already mature. Alternatively, bigger fish should have bigger ovaries, which is connected with an increase in body depth. Also, DCA analysis confirmed a difference between mature males and females in this specific character, even when this effect based on simple comparison by ANOVA was not recorded.

The development was slightly different in males. More characters developed with positive allometry, which would mean faster growth of traits in adult males than in juveniles, which is probably related to investments in reproduction. All these characters were connected with body size, which will make the male body more robust. It is highly connected with the reproductive behaviour of males, when they try to attract more females and protect the nest against other fish species. In this way, they increase the ability of youth survival (Katano and Maekawa, 1997). Also in males were some characters (connected mainly with length and depth of the body) which developed with split linear regression. Based on the results from statistics and TRA it is obvious that topmouth gudgeon is very flexible in forming variable phenotypes when reaching new environments. There are also differences within the population and development in males and females seems to be different. For a complex view of changes in morphology the further testing of the external body shape by geometric analysis is necessary and thus it will be the next step in our research.

Anyhow, the appropriate question is not connected just with the morphology of this fish species, but also with the possible scenario of climate change and topmouth gudgeon's invasion. Warmer water can give the topmouth gudgeon the possible chance of even increasing its invasive potential, because temperature can also have multiple effects on reproduction. Fluctuating thermal regimes can directly influence the timing and duration of spawning and the development and survival of juvenile fish (Fobert et al., 2011). As mentioned above, the population in Lake Licheńskie changed reproductive parameters as well as the amount of batches (increased up to five batches in the spawning season; Záhorská et al., 2013a). Besides that, global climate change will probably cause warmer water temperatures in northern-latitude lakes. This may cause seasonally stressful conditions for coldwater-adapted fish species, but may provide suitable thermal conditions to allow non-native warmer fish species (as well as the other organisms) to thrive in these lakes (Sharma et al., 2007). From this point of view, the Lake Licheńskie gives us a unique option to imagine the composition of future fish communities in the present coldwater lakes. The building of the cooling system for the Konin and Patnów power plants caused an increase in the average temperatures of 5 to $7{ }^{\circ} \mathrm{C}$ and the inflow of warm water from the power plants has affected the wildlife in the lakes. The modifications of hydrological, thermal and trophic conditions impact not just the structure of the fish assemblages, but also the development of zooplankton in Lake Licheńskie. It is limited by high mortality that occurs in the cooling system, the continual weakening of populations, water heating and short retention time, and pressure from planktivorous fish (Ejsmont-Karabin and Węgleńska, 1988). Along with the development of submerged vegetation which is formed by the invasive aquatic plants Najas marina and Vallisneria spiralis, the relative density of topmouth gudgeon has also increased. The consequences of the dispersal of topmouth gudgeon are not difficult to predict. Its juveniles are planktivorous, thus they compete for food with other species and in this way they also affect the abundance of native fish populations. Probably thereby, the coldwater species such as pikeperch (Sander lucioperca), pike (Esox lucius) and perch (Perca fluviatilis) typical of this region have disappeared, or occur at very low densities (Kapusta et al., 2008).

Finally, predictions of how climate change will affect native and non-native species globally are impeded by uncertainties about how multiple environmental factors will interact to influence the distribution and abundance of aquatic organisms (Helmann et al., 2008; Fobert et al., 2011). It will probably change the aquatic ecosystems and the most flexible and the most plastic species will be the most successful. Topmouth gudgeon demonstrates high phenotypic plasticity in all parameters, from reproduction to morphology, and because of this it is one of the most invasive species in any environment it reaches. Thus, we can expect it will be successful even if the climate changes radically. 


\section{ACKNOWLEDGEMENTS}

Authors would like to thank A. Kapusta for collection of material from Poland. This study was funded by the Slovak Scientific Grant Agency (Project No. 1/0392/12).

\section{REFERENCES}

Andersson M., 1994. Sexual Selection. Princeton University Press, New Jersey, 624 p.

Atkinson D., 1994. Temperature and organism size - a biological law for ectotherms. Adv. Ecol. Res. 25, $1-58$.

Baruš V., Kux Z. and Libosvársky J., 1984. On Pseudorasbora parva (Pisces) in Czechoslovakia. Folia Zool., 33, 5-18.

Bănărescu P.M., 1999. Freshwater Fishes of Europe, Vol 5/1. Cyprinidae 2/1, Aula-Verlag, Wiebelsheim, 207-224.

Berrigan D. and Scheiner S.M., 2004. Modeling the evolution of phenotypic plasticity. In: DeWitt T.J. and Scheiner S.M. (eds.), Phenotypic Plasticity, Oxford University Press, Oxford, 82-97.

Britton J.R., Davies G.D. and Brazier M., 2008. Contrasting life history traits of invasive topmouth gudgeon (Pseudorasbora parva) in adjacent ponds in England. J. Appl. Ichthyol., 24, 694-698.

DeMaster D.P., 1978. Calculation of the average age of sexual maturity in marine mammals. J. Fish. Res. B. Can., 35, 912-915.

Dhillon R.S. and Fox M.G., 2004. Growth-independent effects of temperature on the life history traits of Japanese medaka (Oryzias latipes). Copeia, 2004(1), 37-45.

Ejsmont-Karabin J. and Węgleńska T., 1988. Spatial distribution of the zooplankton and its population features in two lakes of different heated-water through-flow. Pol. J. Ekol., 36, 203-230.

Fobert E., Fox M.G., Ridgway M. and Copp G.H., 2011. Heated competition: how climate change will affect non-native pumpkinseed Lepomis gibbosus and native perch Perca fluviatilis interactions in U.K. J. Fish Biol., 79, 1592-1607.

Fox M.G., 1994. Growth, density, and interspecific influences on pumpkinseed sunfish life histories. Ecology, 75, 1157-1171.

Fusco G. and Minelli A., 2010. Phenotypic plasticity in development and evolution: facts and concepts. Phil. Trans. R. Soc. B, 365, 547-556.

Garland Jr T. and Kelly S.A., 2006. Phenotypic plasticity and experimental evolution. J. Exp. Biol., 209, 2344-2361.

Gozlan R.E., Andreou D., Asaeda T., Beyer K., Bouhadad R., Burnard D., Caiola N., Cakic P., Djikanovic V., Esmaeili H.R., Falka I., Golicher D., Harka A., Jeney G., Kováč V., Musil J., Nocita A., Povz M., Poulet N., Virbickas T., Wolter C., Tarkan S.A., Tricarico E., Trichkova T., Verreycken H., Witkowski A., Zhang C.G., Zweimueller I. and Britton R.J., 2010. Pan-continental invasion of Pseudorasbora parva: towards a better understanding of freshwater fish invasion. Fish Fish., 11, 315-340.

Helmann J.J., Byers J.E., Bierwagen B.G. and Dukes J.S., 2008. Five potential consequences of climate change for invasive species. Conserv. Biol., 22, 534-543.

Hogan C.M., 2007. Fish morphology. In: Cleveland C.J. (ed.), Encyclopedia of Earth, Washington DC.

Kapusta A., Bogacka-Kapusta E. and Czarnecki B., 2008. The significance of stone moroko, Pseudorasbora parva (Temminck and Schlegel), in the small-sized fish assemblages in the littoral zone of the heated Lake Licheńskie. Arch. Pol. Fish., 16, 49-62.

Katano O. and Maekawa K., 1997. Reproductive regulation in the female Japanese minnow, Pseudorasbora parva (Cyprinidae), Environ. Biol. Fish. 49, 197-205.

Kitano J., Mori S. and Peichel C.L., 2007. Sexual Dimorphism in the External Morphology of the Threespine Stickleback (Gasterosteus aculeatus). Copeia, 2, 336-349.

Kováč V., Copp G.H. and Francis M.P., 1999. Morphometry of the stone loach, Barbatula barbatula: do mensural characters reflect the species' life history thresholds? Environ. Biol. Fish., 56, 105-115.

Kotusz J. and Witkowski A., 1998. Morphometrics of Pseudorasbora parva (Schlegel, 1842) (Cyprinidae: Gobininae), a species introduced into the Polish waters. Acta Ichthyol. Piscat., 28, 3-14. 
Nikolskij G.V., 1956. Ryby basseina Amura [Fishes of the Amur Catchment] (in Russian), Izdatelstvo Akademii Nauk SSSR, Moskva, 551 p.

Okada Y., 1961. Studies on the freshwater fishes of Japan. J. Fac. Fish. Pref. Univ. Mie, 4, 267-890.

Pigliucci M., Murren C.J. and Schlichting C.D., 2006. Phenotypic plasticity and evolution by genetic assimilation. J. Exp. Biol. 209, 2362-2367.

Robinson B.W. and Wilson D.S., 1996. Genetic variation and phenotypic plasticity in a trophically polymorphic population of pumpkinseed sunfish (Lepomis gibbosus). Evol. Ecol., 10, 631-652.

Schluter D., 2001. Ecology and the origin of species. Trends Ecol. Evol., 16, 372-380.

Sharma S., Jackson D.A., Minns C.K. and Shuter B.J., 2007. Will northern fish populations be in hot water because of climate change? Glob. Change Biol., 13, 2052-2064.

Sokal R.R. and Rohlf F.J., 1981. Biometry. The principles and practice of statistics in biological research, 2nd edition. W. H. Freeman, San Francisco, 859 p.

Šumer S., Kováč V., Povž M. and Slatner M., 2005. External morphology of a Slovenian population of pumpkinseed Lepomis gibbosus (L.) from a habitat with extreme thermal conditions. J. Appl. Ichthyol., 21, 306-311.

Trippel E.A. and Harvey H.H., 1987. Reproductive responses of five white sucker (Catostomus commersoni) populations in relation to lake acidity. Can. J. Fish. Aquat. Sci., 44, 1018-1023.

Wootton R.J., 1984. Energy allocation in the threespine stickleback. In: Bell M.A. and Foster S.A. (eds.), The Evolutionary Biology of the Threespine Stickleback, Oxford University Press, Oxford, 144-143.

Záhorská E. and Kováč V., 2013. Environmentally induced shift in reproductive traits of a long-term established population of topmouth gudgeon (Pseudorasbora parva). J. Appl. Ichthyol., 29, 218-220.

Záhorská E., Kováč V., Falka I., Beyer K., Katina S., Copp G.H. and Gozlan R.E., 2009. Morphological variability of the Asiatic cyprinid, topmouth gudgeon Pseudorasbora parva, in its introduced European range. J. Fish Biol., 74, 167-185.

Záhorská E., Kováč V., Švolíková K. and Kapusta A., 2013a. Reproductive parameters of topmouth gudgeon from a heated Lake Licheńskie (Poland). Cent. Eur. J. Biol. (in press).

Záhorská E., Švolíková K. and Kováč V., 2013b. Do invasive populations of topmouth gudgeon (Pseudorasbora parva, Temminck and Schlegel) from disturbed and undisturbed habitats follow different life-histories? Int. Rev. Hydrobiol., 98, 61-70. 